\title{
Access to Antibiotics through Prescription and Non-Prescription Media in Private Pharmacies in Lomé, Togo
}

\author{
Yao Potchoo1 $^{*}$, Salou Mounerou${ }^{1}$, Rasak Soukouratou${ }^{1}$, Dossim Sika ${ }^{1}$, Koumavi D. Ekouevi ${ }^{2}$, \\ Yerima Mouhoudine1, Prince-David Mireille³, Anoumou Y. Dagnra ${ }^{3}$ \\ ${ }^{1}$ Département des Sciences pharmaceutiques et biologiques, Faculté des Sciences de la Santé, Université de Lomé, Lomé, Togo \\ ${ }^{2}$ Département de Santé Publique, Faculté des Sciences de la Santé, Université de Lomé, Lomé, Togo \\ ${ }^{3}$ Département des Sciences fondamentales, Faculté des Sciences de la Santé, Université de Lomé, Lomé, Togo \\ Email: *ypotchoo@hotmail.com
}

How to cite this paper: Potchoo, Y., Mounerou, S., Soukouratou, R., Sika, D., Ekouevi, K.D., Mouhoudine, Y., Mireille, P.-D. and Dagnra, A.Y. (2019) Access to Antibiotics through Prescription and Non-Prescription Media in Private Pharmacies in Lomé, Togo. Pharmacology \& Pharmacy, 10, 31-47.

https://doi.org/10.4236/pp.2019.101004

Received: December 10, 2018

Accepted: January 14, 2019

Published: January 17, 2019

Copyright $\odot 2019$ by author(s) and Scientific Research Publishing Inc. This work is licensed under the Creative Commons Attribution International License (CC BY 4.0).

http://creativecommons.org/licenses/by/4.0/ (c) (i) Open Access

\begin{abstract}
Objectives: The present study was conducted to describe and analyze antibiotic demands via prescription and non-prescription media received in private pharmacies in Lomé. Methods: A cross-sectional study was conducted in 26 private pharmacies in Lomé (Togo) from August to October 2013. The study was based on a survey conducted with a standardized questionnaire to collect data representing the daily activity of the pharmacies. Data on prescription documents, non-prescription media, patients' and prescribers' identification, and antibiotics requested were collected and analyzed. Key findings: During the study period, 596 antibiotic prescriptions were collected. Various prescription and non-prescription media permitted available antibiotic access in private pharmacies. Seventy-nine percent $(79 \%)$ of the received orders contained one antibiotic. All categories of health care professionals were found among antibiotic prescribers. Prescribers were not identifiable in $40.2 \%$ of all prescription tools received for antibiotics demand. Forty-four percent (44\%) of antibiotic orders were supported by a prescription. The study found that many people ordering antibiotic (61\%) were not the direct users. Some elements of prescription compliance were mentioned at the rate of $82 \%, 44.7 \%$ and $59 \%$ (date, prescribers' identity and qualification), $3 / 4$ of the prescription material (patients' identity and sex), more than $87 \%$ (accuracy of the dosage), $79.7 \%$ (oral route of administration) and less than $1 / 3$ (duration of treatment). The results also indicated that Beta-lactams (41\%), quinolones (17\%), and 5-nitroimidazoles (15\%) were the most prescribed classes of antibiotics. Conclusions: The study revealed that more than half of the antibiotics orders, received in pharmacies were non-compliant. This calls for an awareness of healthcare workers and populations on the rational use of antibiotics.
\end{abstract}


Access to antibiotics should be further controlled (prescription dispensing), community should ban other media of obtaining antibiotics without a prescription and avoid particularly antimicrobial self-medication.

\section{Keywords}

Antibiotics, Prescription Media, Non-Prescription Media, Antibiotic User, Prescription Compliance, Private Pharmacy, Togo

\section{Introduction}

Medicines are the weapons to fight against disease but may also cause serious harm when used improperly [1]. In developing countries, drug monitoring system is very poor and it is very easy to buy any drug with or without prescription [2]. This inappropriate way administering medicine is one of the key elements which promote irrational use of medicine [3]. More than $50 \%$ of all medicines prescribed, dispensed, or sold around the globe are somehow inappropriate and $50 \%$ of the patients fail to take medicines appropriately [4]. The irrational use of medicines may occur in different forms but self-medication is the most frequent forms [5]. Besides, the quality of drugs and inappropriate use of antibiotics constitute a growing concern [6]. Both non-quality drugs and inappropriate use can lead to some outcomes such as excess healthcare cost, adverse drug reaction, allergic reactions, toxic poisoning, exacerbation or extension of critical illness and antibiotic resistance [7]. In developing countries like Togo, people depend more on pharmacies due to expediency, shorter waiting time, cost reduction, and flexible opening hours [8] [9]. In public and private settings, we observe overprescriptions, misuse of antibiotics, lack of data on antibiotic consumption, lack of supervisory program and guidelines for antibiotic use and low adherence to treatment guidelines [10] [11] [12] [13]. Antimicrobial resistance (AMR) has become a global public health issue. ATBs should be prescribed after performing an antibiogram test. However, in our settings, because of the time frame to deliver the results of this laboratory test (24 to 48 hours), nearly $80 \%$ of ATBs prescriptions are probabilistic [14]. In addition, in sub-Saharan countries such as Togo, it is also observed that ATBs' prescription is no longer under the sole responsibility of the physician. Thus, it is not rare to see some customers ordering ATBs just to provide well-being [15]. The outcome of these generalized prescriptions and presumably overconsumption of ATBs could lead to the emergence of bacteria strains multi-resistant to ATBs available [15] [16]. As shown by several studies, Togo does not escape the phenomenon of AMR [17]. This study aims at describing and analysing ATBs' demands through prescribed or non-prescribed materials received in private pharmacies of Lomé (Togo).

\section{Methods}

A survey was carried out in private pharmacies in Lomé from August to October 
2013. The choice of Lomé for this study is justified by the fact that it is the largest city and at the same time the capital of Togo. It is a cosmopolitan city characterized by a high concentration of care facilities (public, private and confessional), drug distribution structure, private pharmacies, health personnel of all categories (teachers, doctors, surgeons, medical-assistants, nurses, midwives...) and a better organized and more efficient health system. As a result, health needs are much more pronounced, with the attendant need for access to medicines, particularly antibiotics with or without prescriptions, which is the current problem because of the potential risk of resistance.

It was a cross-sectional study designated to provide a descriptive analysis of ATBs' orders (or demands) received in private pharmacies. Figure 1 is the map of the licensed pharmacies of Lomé during the study.

\subsection{Eligible Pharmacies}

Inclusion Criteria

All the prescriptions' media containing at least one ATB were collected.

Exclusion Criteria

The prescriptions' tools containing antibiotics for which the carriers refused to take part in our study.

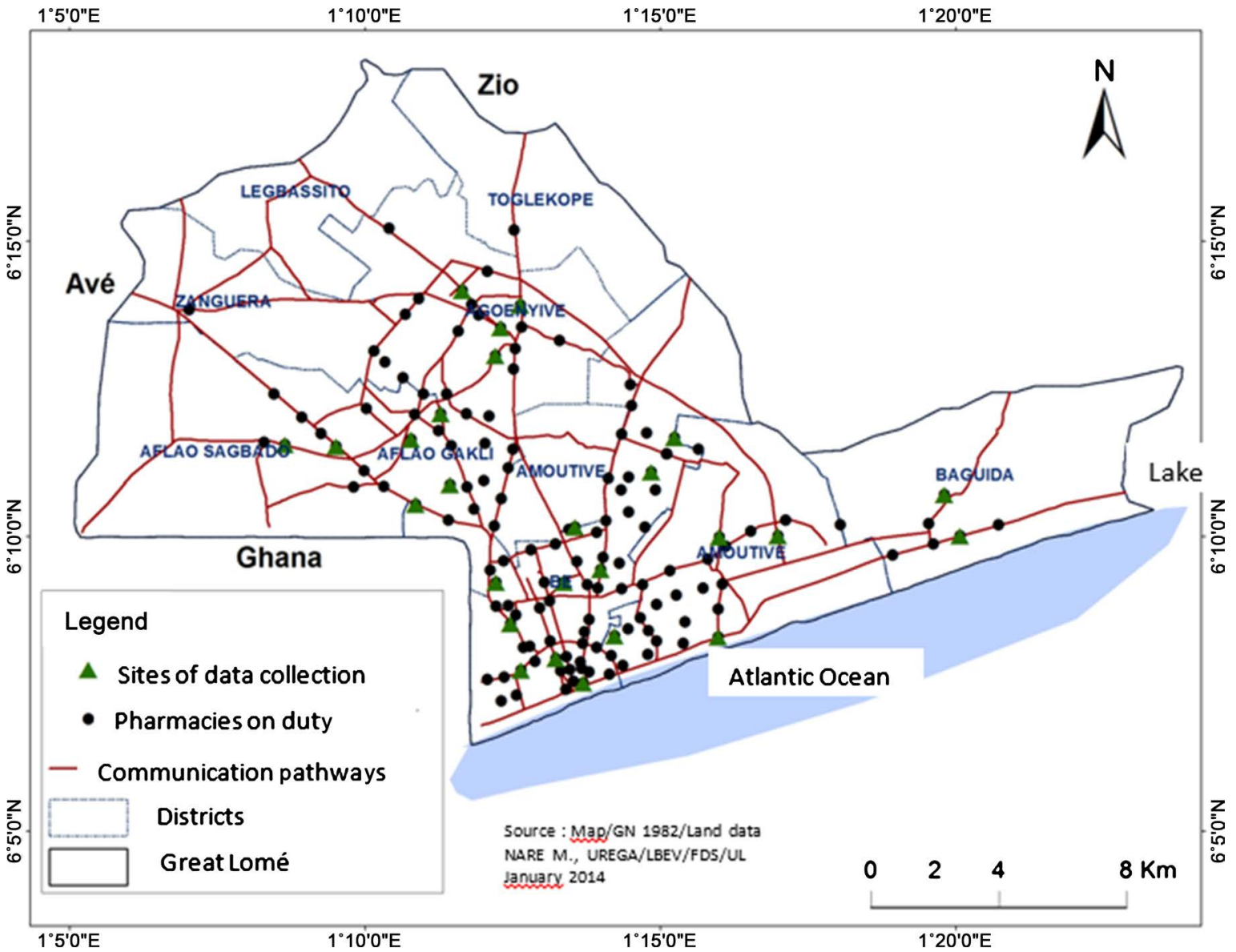

Figure 1. Map of the localization of licensed pharmacies during data collection period. 


\subsection{Data Collection}

We used the 2013 second semester duty program to select data collection sites. The area of Lomé was divided into 7 parts rated from 1 to 7 . The collections' sites (private pharmacies) were selected randomly in each part. The pharmacies eligible for data collection are shown in Figure 2.

We designed a questionnaire to collect the following information:

- description of the prescription bearer: user or issuer;

- description of the prescription document: prescription sheet, health record book, piece of paper, text message, drug packaging, oral request, and other media;

- information on prescribed molecules: International Common Denomination (ICD), brand name, dosage, duration of treatment, route of administration;

- qualification of the prescriber: physician (general practitioner, specialist), resident medical student, physician-assistant, nurse, mid-wife, and other prescribers (responsible, technical health officer, nursing aid, health scientist);

- prescription issuing facility: university hospital, intermediate health care center (regional and district hospitals), health center, denominational facility, private facility, or unknown issuing facility;

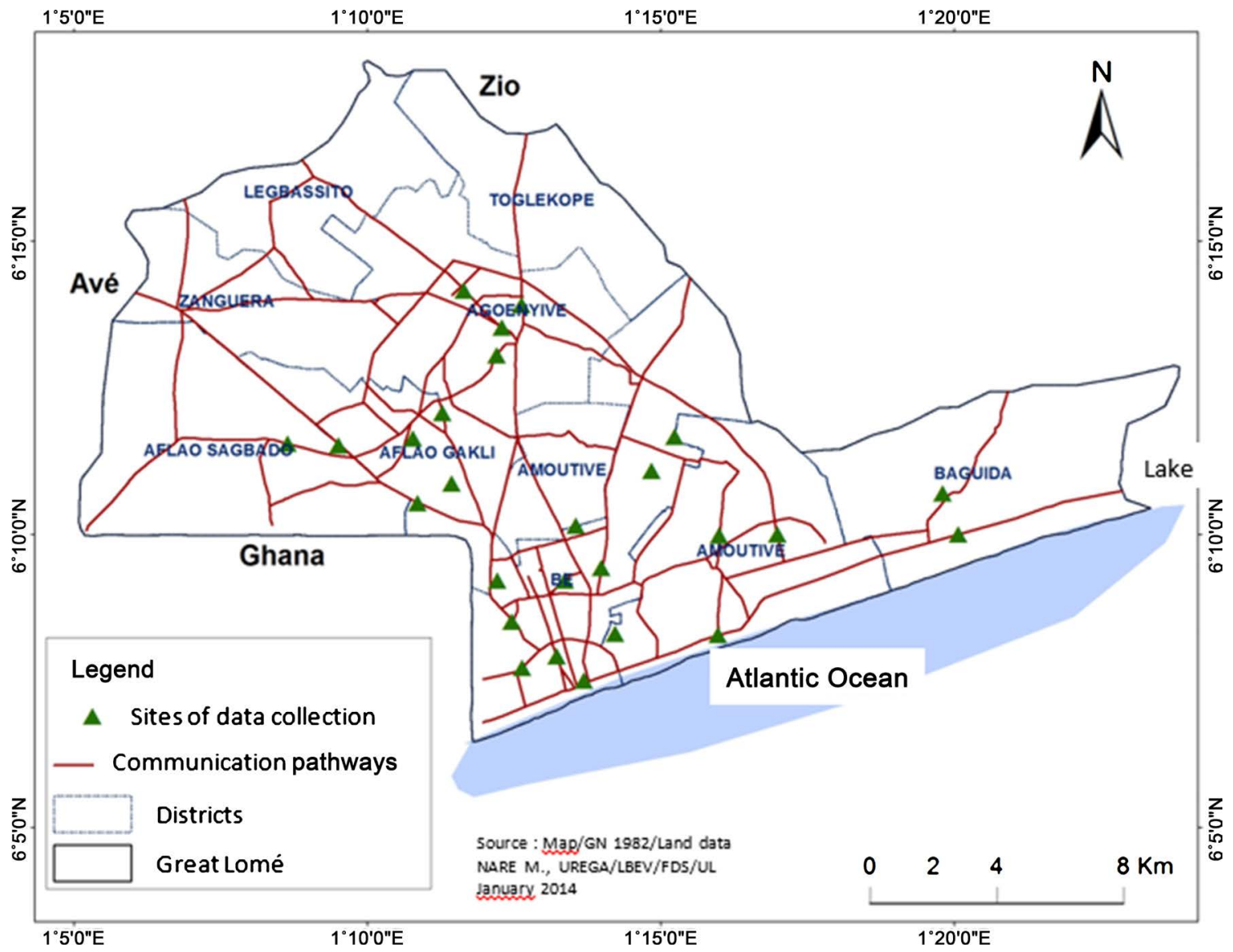

Figure 2. Data collection sites. 
- patient information: identity, age, weight, and gender.

All drug prescription documents containing at least one ATB received at the research sites at the time of the survey were included in the study. The regulatory compliance of prescription documents was checked according to the standards of the World Health Organisation (WHO) [18]. The data were processed and analyzed using Epi Data 3.1 and Microsoft Excel software.

\section{Results}

596 antibiotic demand materials were received across 26 private eligible pharmacies during the period of the study.

\subsection{Antibiotic Demand Materials and Their Delivery in Non-Prescription Pattern}

About $61.0 \%(n=366)$ of people who requested ATBs were not the direct beneficiaries. Patient's verbal requests $(23.3 \%)$ dominated among the demands without prescription followed by other media (8.9\%) and external packaging $(3.7 \%)$. The different kinds of antibiotic demand received are summarized in Table 1.

\subsection{Regulatory Compliance of Medical Prescriptions}

Forty-four percent (44\%) of ATB's requests were made by submitting a formal prescription (prescription sheet $(32.4 \%)$ and health record book $(11.6 \%), \mathrm{n}=$ 262) (Table 1). Seventy-nine $(79 \%, n=471)$ percent of the received media contained one ATB prescribed.

Eighty-two $(82 \%, \mathrm{n}=310)$ percent of paper prescription media (prescription sheet, health record book, piece of paper, $n=378$ ) were dated. Prescribers' qualifications were mentioned in $59 \%$ of the orders registered. Three out of four paper prescription media mentioned patients' identity and sex. The age of children is reported on $27 \%$ of prescription media and children's weight on $23.1 \%$ (Figure 3 ).

Fifty one out of 193 antibiotic prescribers (40.2\%) were not identified. The prescribers' profile is summarized in Table 2. They were dominated by physician (18.8\%) followed by other prescribers (16.7\%), nurses (11.4\%), physician-assistants

Table 1. Different prescriptions' documents $(n=596)$ collected in private pharmacies.

\begin{tabular}{cccc}
\hline Type of access & Type of document & $\mathrm{n}$ & Frequency (\%) \\
\hline \multirow{2}{*}{ With prescription } & Prescription sheet & 193 & 32.4 \\
& Health record book & 069 & 11.6 \\
Piece of paper & 116 & 19.5 \\
Patient's verbal request & 139 & 23.3 \\
External packaging & 022.7 \\
& Short message system & 004 & 00.7 \\
Other media & Total & 053 & 08.9 \\
\hline
\end{tabular}




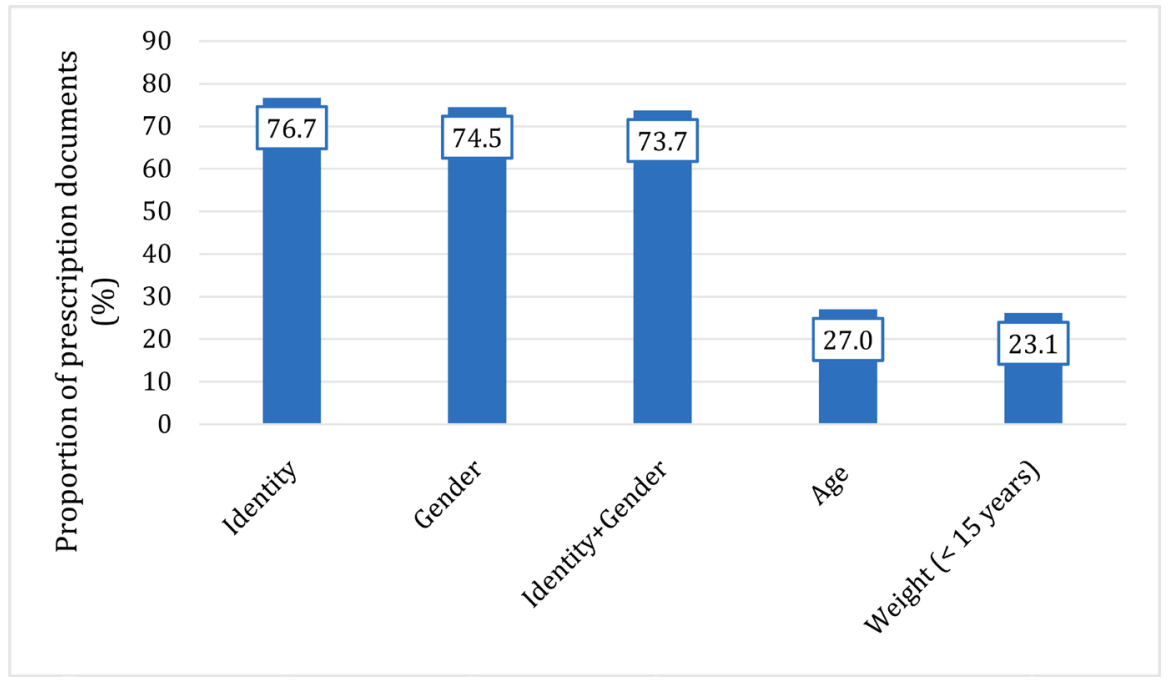

Figure 3. Availability of patient information on prescription documents $(n=378)$.

Table 2. Prescription documents according to prescribers' qualification $(\mathrm{n}=378)$.

\begin{tabular}{cccccc}
\hline & Prescription sheet & Health record book & Piece of paper & Total & (\%) \\
Physicians & 63 & 03 & 05 & 71 & 18.8 \\
Physician assistants & 19 & 14 & 08 & 41 & 10.9 \\
Midwives & 02 & 06 & 00 & 08 & 02.1 \\
Nurses & 26 & 10 & 07 & 43 & 11.4 \\
Other prescribers & 32 & 13 & 18 & 63 & 16.7 \\
Unidentified prescribers & 51 & 23 & 78 & 152 & 40.2 \\
\hline
\end{tabular}

(10.9) and midwives (2.1\%).

\subsection{Therapeutic Scheme of the Prescription}

The oral route $(79.7 \%)$ was the most frequent administration way reported on antibiotic demand media $(n=596)$. The accuracy of the dosage (strength) was documented by the different types of healthcare facilities as shown in Figure 4 . The mention rate was more than $85 \%$ for confessional, regional hospital, health center, private and teaching hospital and about $68 \%$ for unknown health care facilities.

More than $87 \%$ of prescribers mentioned the dosage on prescription documents as shown in Figure 5. In decreasing order, the dosage specification was physicians (94.4\%) followed by nurses (93\%), physician-assistants (90.2\%), midwives (87.5\%) and other prescribers (79.4\%).

The duration of the treatment was not specified in more than $3 / 4$ of the prescriptions issued from each type of facility (Figure 6). The lack of mention of this order parameter of quality is in decreasing frequency: private facilities (89.3\%), regional hospital (82.1\%), teaching hospital (77.8\%) and health center (75\%). The duration of treatment was correctly mentioned on $22.2 \%$ of prescription media for teaching hospital, $21.2 \%$ for health center, $17.9 \%$ for regional 
hospital and $10.1 \%$ for private facility.

Figure 7 shows that, $100 \%$ of midwives do not mention the duration of treatment; followed by other prescribers (95.2\%), physician-assistants (80.5\%), nurses (79.0) and physicians (63.4\%). Less than 50\% of each category of prescribers reported correctly the duration of treatment (Figure 7). The frequency of reporting the duration of treatment is $33.8 \%$ for physicians, $17.1 \%$ for physician-assistants and $14 \%$ for nurses.

\subsection{Classes of Antibiotics Requested}

The most prescribed or requested classes of ATBs were beta-lactams (40.9\%),

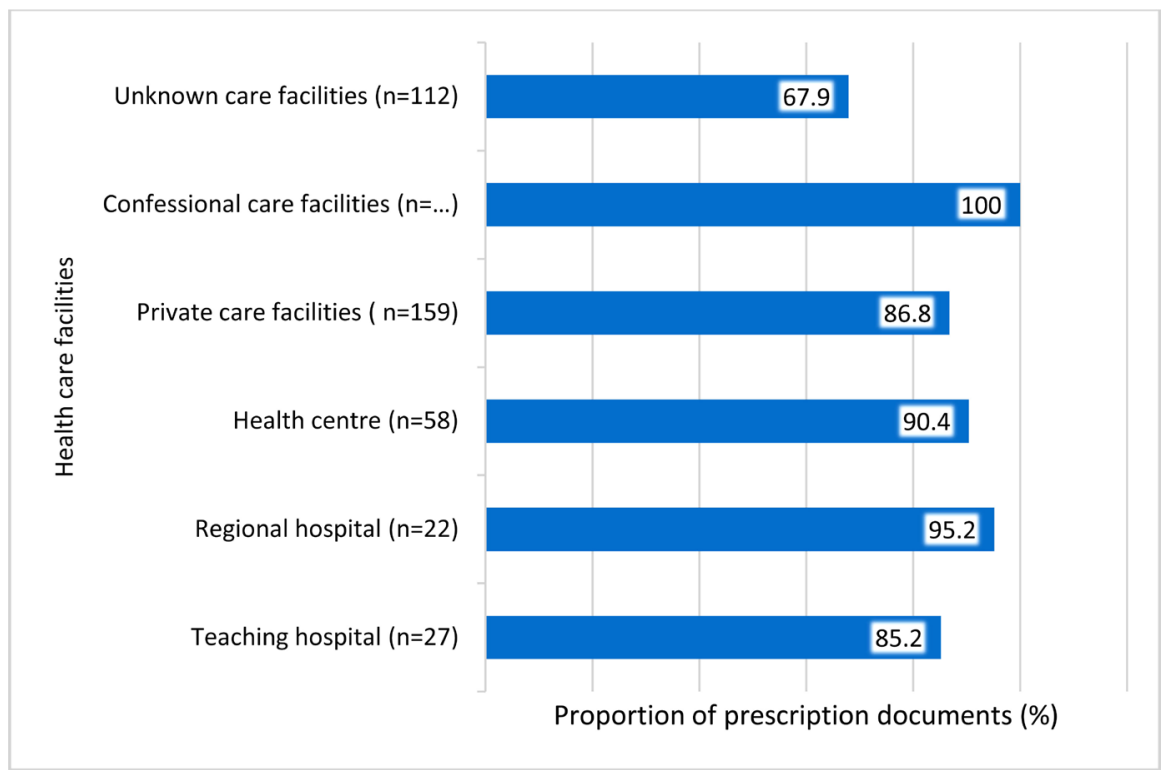

Figure 4. Distribution of prescription documents $(n=378)$ specifying the dosage according to the level of the health care facilities.

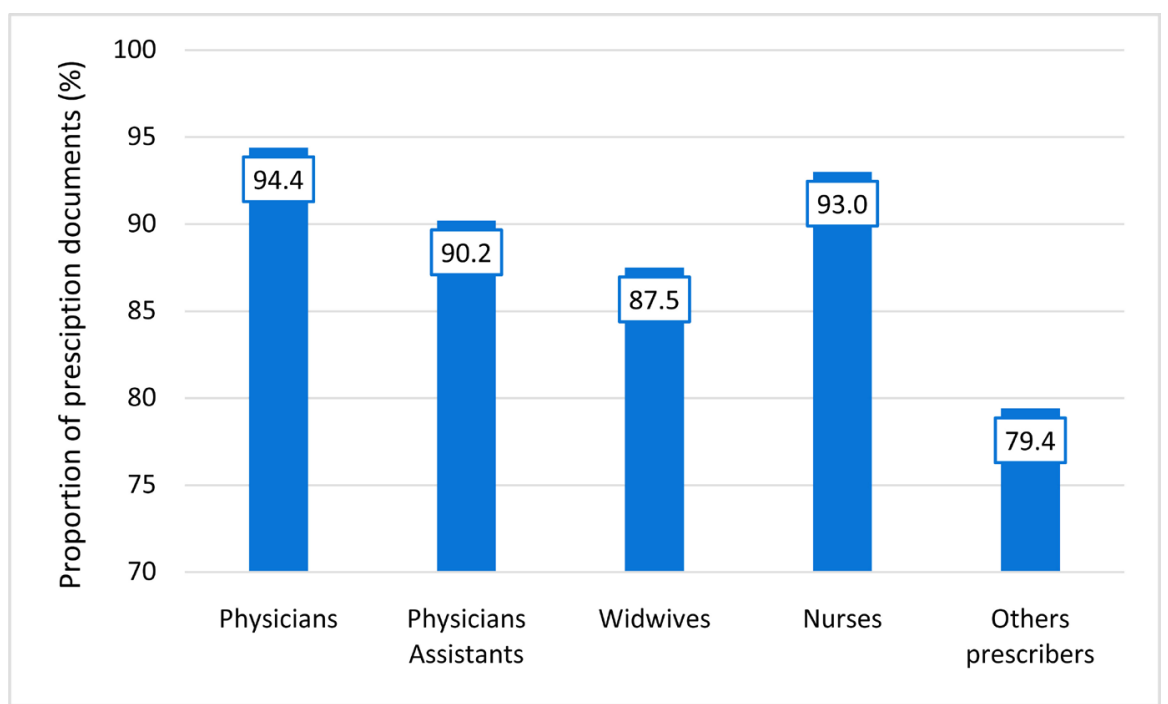

Figure 5. Distribution of prescription documents $(n=378)$ specifying the dosage according to the prescribers' qualification. 


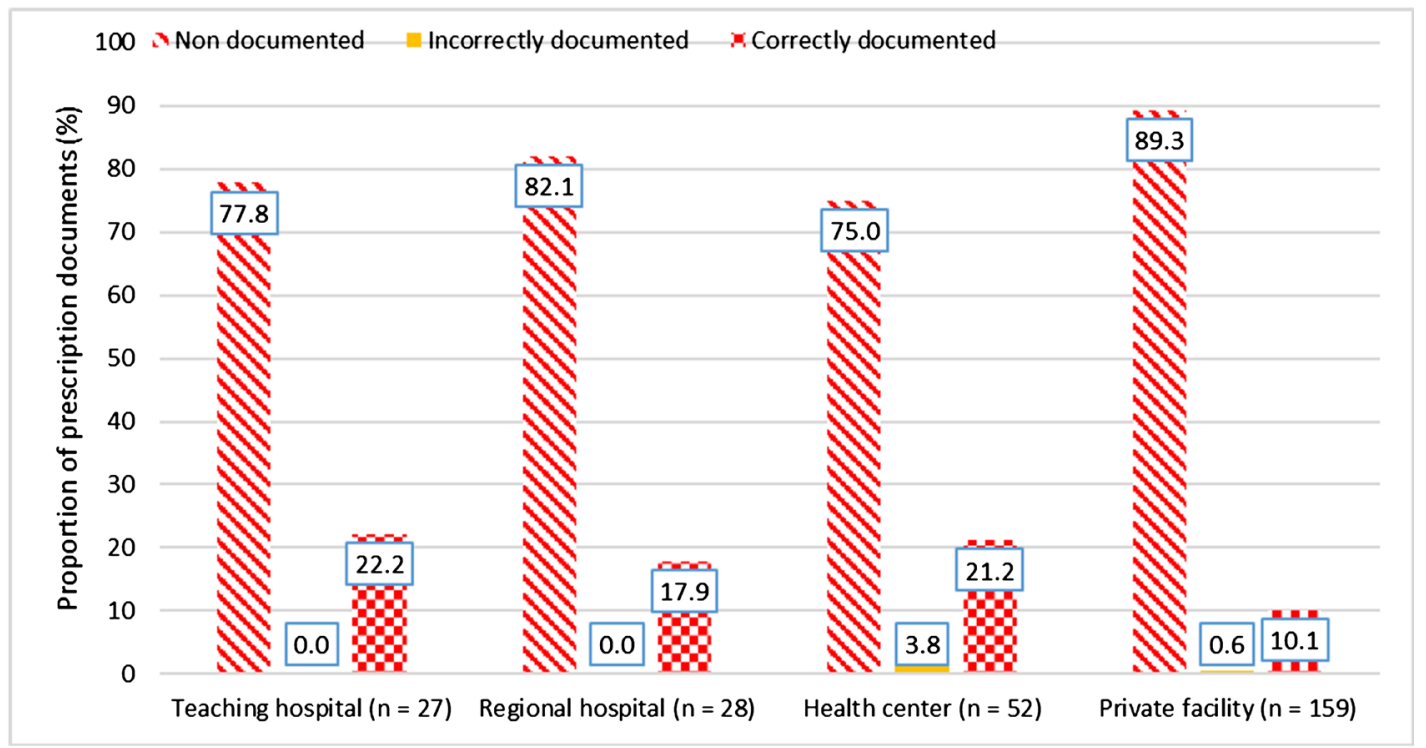

Figure 6. Distribution of prescription documents $(n=378)$ specifying the duration of treatment according to the category of the health care facilities.

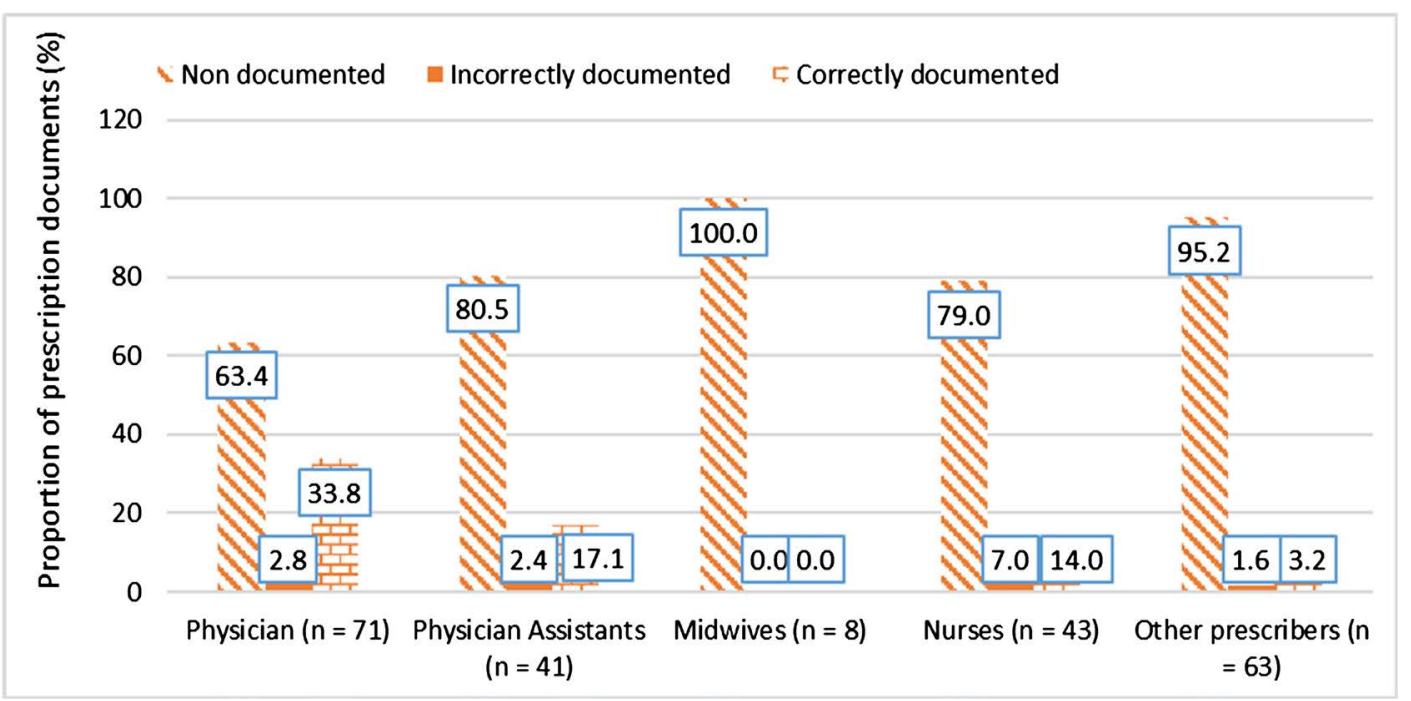

Figure 7. Distribution of prescription documents $(n=378)$ specifying the duration of treatment according to the prescribers' qualifications.

quinolones (16.7\%), 5-nitro-imidazoles (15.3\%), aminosides (7.7\%) and macrolides (5.7\%) as shown in Figure 8.

\section{Discussion}

\subsection{Limits of the Study}

The present work did not collect data for clinical use of antibiotic requested and patient recovery; hence the treatment outcome could not be determined. Moreover, we did not consider self-medication and its determinants.

As reported by some authors in their studies, information on antibiotic consumption is needed to control the development and spread of resistant bacteria 


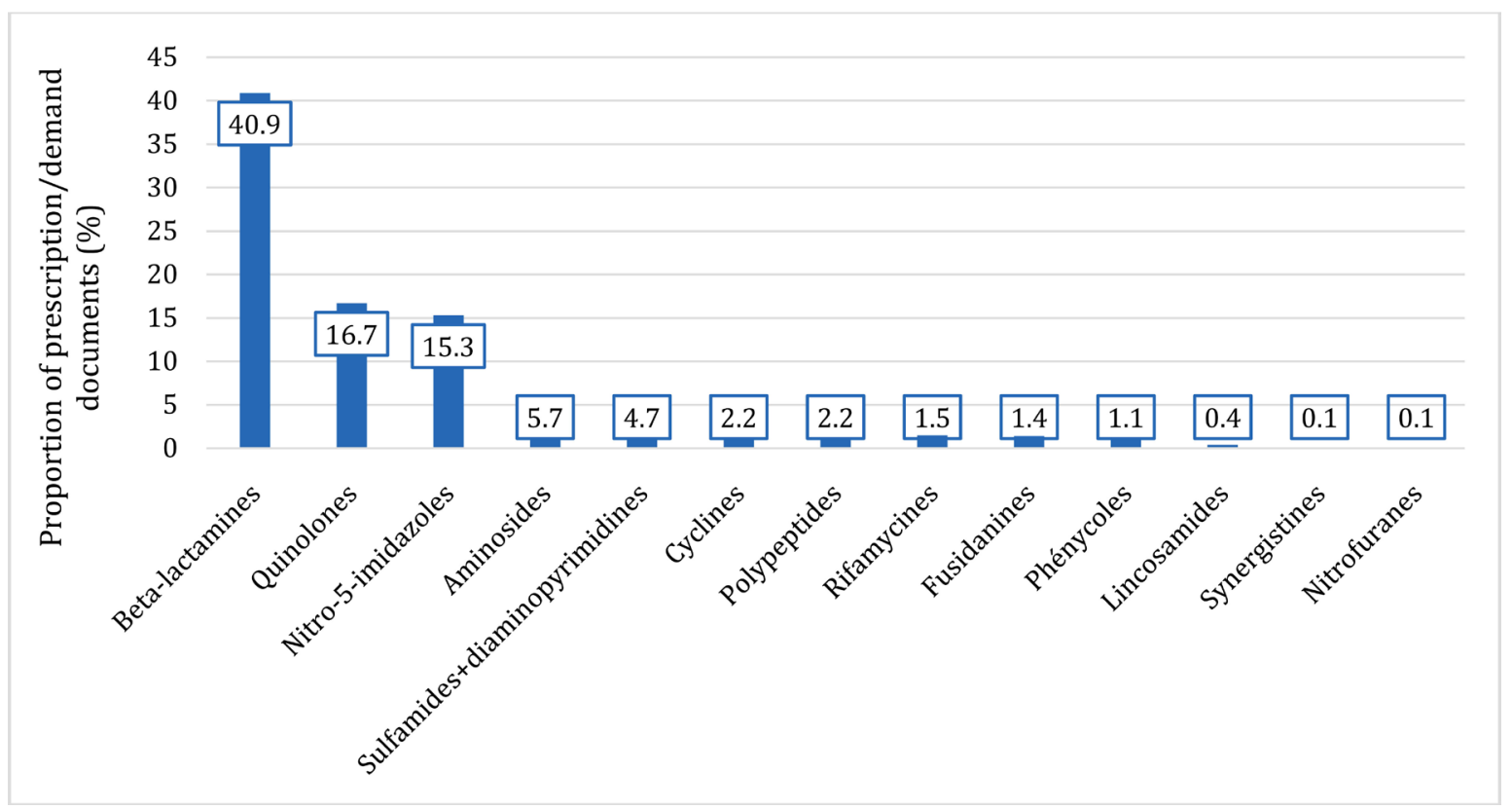

Figure 8. Different classes of antibiotics prescribed or requested.

[19]. Prudent use of antimicrobials helps to prevent the relentless increase in resistance [20].

\subsection{Antibiotic Demand Materials and Their Delivery in Non-Prescription Pattern}

About $61.0 \%(\mathrm{n}=366)$ of the people who requested ATBs were not the direct users. To the best of our knowledge, there is little literature related to this topic. In our context, it is common that the applicant for medicines in general and ATB in particular who visits private pharmacies is not the direct beneficiary but rather a friend or a parent or even a child. This further increases the risk of antibiotic therapy since in case of advice for an adequate use of ATB, it is not sure that these pieces of advice will be faithfully transmitted to the real beneficiary of the treatment. This situation could cause misunderstanding and non-compliance with the treatment by the patient, which is a source of antimicrobial resistance.

Patient's verbal requests (23.3\%) dominated among antibiotic demands without prescription. They were followed by other media (8.9\%) and external packaging (3.7\%). There is not much literature concerning the media through which clients access antibiotics in private pharmacies. However, in Northern Ireland, more than $25 \%$ and $55 \%$ respectively of all systemic and topical antimicrobials were initiated following telephone consultations [21]. This high rate of verbal requests and the use of external package and other media observed in our study show a practice of antibiotic self-medication favored by the weakness in antibiotic policies that could amplify the phenomenon of antimicrobial resistance.

\subsection{Antibiotic Demand Materials in Prescription Pattern}

Forty-four percent (44\%) out of 596 ATBs' demand documents collected during 
the study period were supported by a formal prescription (prescription sheet, $32.4 \%$ and health record book, 11.6\%). Chem et al. reported an overall percentage prescription with antibiotics of $36.7 \%$ in primary health care facilities in Cameroon [20]. In the evaluation of medicines administering pattern in private pharmacies in Rajshahi (Bangladesh), Saha and Hossain reported $65.83 \%$ of antimicrobials dispensed on prescription [1]. In hospitalized population, Prah et al. indicated 55.2\% of antibiotics on prescriptions in primary facility in Ghana [22], and Diarra (2007) observed a higher rate of antibiotic prescription (99.70\%) during a study conducted at the Point G University Hospital in Bamako [23]. In urban areas, the rate of ATB prescription of our study is lower than that reported by Rajshahi in Bangladesh. At hospital, the rate of ATB prescription seems to increase from primary health care setting to teaching hospital setting. Globally, it is difficult to compare these results because various factors influence antibiotic prescription. These factors include patient characteristics such as low-socioeconomic status, age and co-morbidity; physician factors (educational qualification, experience, source of updating knowledge); and practice setting [24]-[29]. Moreover, other factors related to antibiotic prescription are diagnostic uncertainty, perceived demand and expectation from the patients, practice sustainability, influence from medical representatives and inadequate knowledge [30] [31] [32]; antibiotic availability, prescriber in-service training [33]; influence of patient demand for antibiotics on doctor's decision [34] [35], cultural aspects [36] etc. In this regard, it is necessary to understand physicians' prescription behaviour in order to develop interventions that will effectively improve the use of antibiotics [20].

Seventy-nine percent $(79 \%)$ of the received documents in private pharmacies contained one ATB prescribed compared to the majority of prescriptions (87.42\%) with one antibiotic in primary health care setting in Cameroon [20]. Almost every $48 \%$ of valid prescriptions had at least one antibiotic in private pharmacies, which is too high [1]. Differences in the incidence of infectious disease [37] probably explain the above different high rate of antibiotic consumption.

\subsection{Regulatory Compliance of Antibiotic Prescriptions}

Our findings are compared with literature data as part of the prescriptions in general practice since antibiotic-specific prescription data are rare.

Eighty-two $(82 \%, \mathrm{n}=310)$ percent of paper prescription media (prescription sheet, health record book, piece of paper, $\mathrm{n}=378$ ) were dated. In a study conducted in private and public pharmacies among random clients, Potchoo et al. reported that $73.04 \%$ of prescription media specified the date [38]. The date of the prescription (87.0\%) was well mentioned in a study conducted in randomly chosen private pharmacies in Bobo Dioulasso (Burkina Faso) [39] and 56.60\% of medical prescriptions were dated and signed [39]. The date of the prescription enables to determine the validity period of the prescription depending on the country (no time limit to three or six months) [18]. With regards to the signa- 
ture of the prescriber, it is mandatory and is a component of the prescription authentication.

The identity and qualification of the prescribers were mentioned respectively in $44.7 \%$ and $59 \%$ of the orders received. Potchoo et al. reported that prescribers did not mention their name or their qualification in $47.75 \%$ and $33.04 \%$ of cases respectively [38]. Several medical prescriptions did not mention prescribers' identities (75.8\%) and the qualification of the prescriber was missing on $68.4 \%$ of prescriptions in a study carried out by Fofana et al. [39]. In France more than $2 / 3$ of the orders carry the qualification of the prescriber [40] [41]. In Switzerland, $96.1 \%$ of prescriptions mention the qualification of the prescriber [42]. This higher rate of mention in developed countries may be due to the computerization of prescription system in which some information related to prescribers such as name, qualification, address and phone number are pre-printed on the form [18]. This detailed information protects the responsibility in the implementation of the therapy and are useful to identify patient's care route. Besides, it facilitates the communication with the pharmacist. In Togo where dispensation is granted to physician-assistants, nurses and midwives, the mention of the prescriber's qualification will allow to check the health care provider competence, the order authentication or entitlement to prescribe certain drugs in accordance with regulations.

Three out of four paper prescription media mentioned patients' identity and sex. This rate is higher than that observed in the study carried out in 2009 by Potchoo et al. in which the orders did not mention patient's name in $41.18 \%$ of prescription [38]. The age of children is reported on less than one third of prescription media and children's weight on less than one fourth. These low rates of mention of the information related to patient and more particularly to children shows that the prescribers did not respect the regulations in force. Thus, they expose patients to certain drug risks (dispensing an adult dosage for a child in case of lack of children's age and weight) and reduce the medicines' traceability. In the study of Fofana et al., information on the patients was missing such as patient's age in $79.4 \%$ of prescriptions, weight in 26 out of 27 cases of pediatric prescriptions and identity in $21.0 \%$ of prescriptions [39]. Again, the identity of the patient on a prescription form is mandatory [18]. Patient's name allows individualisation and traceability of the prescription and permit to avoid delivery or treatment mistakes. Age, weight and sex are also distinctive features which lead to characterise two patients. Information on weight is required on children's prescription, especially when the dosage is given in $\mathrm{mg} / \mathrm{kg}$ of the patient body weight or in body weight group. The mention of the age is also required especially for children as certain medicines dosage are given in age or age group.

About $40.2 \%$ of ATB prescribers (51/193) were not identified against $33 \%$ as reported by Potchoo et al. in their study [38]. Prescribers' profile was represented by physician (18.8\%) followed by other prescribers (16.7\%), nurses (11.4\%), physician-assistants (10.9) and midwives (2.1\%). A 2007 survey in Bamako, (Mali) examined 1000 prescriptions received in pharmacy. The survey showed 
that $17.90 \%$ of antibiotics prescriptions at the Point G Hospital were issued by a staff comprising technicians, aids and non-residents [23]. Potchoo et al. reported that $31.37 \%$ of physicians, $12.55 \%$ of physician-assistants, $14.71 \%$ of nurses and $8.33 \%$ of midwifes in their study [38] against $17.4 \%$ of physicians, $12.15 \%$ of nurse, $1.52 \%$ of medical trainees and $0.55 \%$ of midwife were observed in the study of Fofana et al. [39]. It should be pointed out that physician-assistants (medical assistants) are a category of trained health professionals between doctors and nurses in Togo for the needs of the national health system. For other health professionals, the differences observed remain at the level of the area of the study (capital of Togo and second city of Burkina Faso). The entitlement to prescribe is assessed according to the qualification of the prescriber to secure the use of prescribed drug. In Togo, the prescriptions of physicians and dentists' are free within their respective competences as in the worldwide. Every country has its own laws and regulations to define which drugs require a prescription and who is entitled to prescribe it [18].

\subsection{Therapeutic Scheme of Antibiotic Prescription}

The accuracy of the dosage was documented by the different types of health care facilities and different category of prescribers but we did not find the data for comparison in literature. More than $87 \%$ of prescribers mentioned the dosage on prescription documents. This rate seems to be improved by sensitizations since Potchoo et al. (2009) report $54.51 \%$ of no dosage mention in their study [38]. The study conducted by Fofana et al. has revealed that pharmaceutical form and dosage were frequently omitted (56.6\%) [39]. El Bara (2013) in Mauritania [43] and Shahaibi et al. (2012) in Oman [44] also found a high proportion of prescriptions without any mention of form or dosage ( $88 \%$ and $35 \%$ respectively). However, the precision of the pharmaceutical form is an important element of the prescription quality because it takes into account the characteristics of the patient (age, preference), the treatment objectives and pharmacokinetic characteristics (speed of action, delay of action, duration of action, bioavailability, prolonged action...) and the drug availability. The omission of the dosage mention expose child patients to certain drug harm (dispensing an adult dosage for a child in case of lack of children's age and weight) and thus reducing the treatment security.

The oral route $(79.7 \%)$ was the most frequent administration way reported on antibiotic demand media $(n=596)$ compared to $54.51 \%$ of non-mention of the route of administration in the study published by Potchoo et al. [38]. The rate of administration route mention recorded in our study is higher than that reported in the study of Fofana et al. in which $95.42 \%$ of route of administration was missing [39]. The author explained this low rate of reference by the fact that some prescribers deduct the route of administration from the pharmaceutical directions for use. However, some drugs exist in the same form but are administrated through distinctive route of administration (for example Nystatin, oral and vaginal tablet) [39]. The omission to indicate the route of administration is a 
source of therapeutic error [45] [46]. Indeed, the route of administration influences the rapidity of action, bioavailability and effectiveness of the drug.

The duration of treatment was not specified in more than 3/4 of prescriptions issued from all type of facility. The frequency of reporting the duration of treatment was less than $50 \%$ (33.8\% for physicians, $17.1 \%$ for physician-assistants and $14 \%$ for nurses) compared with the study of Potchoo et al. in which the rate of mention of this parameter was $38.13 \%$ for physicians, $31.38 \%$ for physician-assistants, $27.06 \%$ for midwifes and $22 \%$ for nurses [38]. Globally, the rate for non-specifying the duration of treatment of the present study is almost similar to that reported by Potchoo et al. in their study (78.04\%) [38] but lower compared to that observed by Fofana et al. who noted a lack of treatment duration on $85.5 \%$ of studied prescriptions [39]. This parameter is determined by taking into account the time necessary to achieve and maintain an effective steady state. The absence of the duration of the treatment can be particularly harmful in the field of anti-biotherapy. Indeed, it can induce a disease relapse, or resistances by insufficient treatment (shorter duration compared to the recommended duration) or lead to the leftover antibiotics stored at home [47] which could be responsible for self-medication and its outcomes.

\subsection{Classes of Antibiotics Requested}

Beta-lactams (40.9\%), quinolones (16.7\%), 5-nitro-imidazoles (15.3\%), aminosides $(7.7 \%)$ and macrolides (5.7\%) were the most purchased classes of ATBs. Musey et al. in a study finds $57.7 \%$ of beta-lactams, $14.9 \%$ of quinolones and $5.9 \%$ of 5-nitro-imidazoles [48]. However, for Coulibaly, the beta-lactams represented $47.4 \%$, followed by aminoglycosides $(28.10 \%)$, quinolones $(10.30 \%)$, and 5-nitro-imidazoles (8.50\%) [49]. In Uganda, the majority of drug shops sold antibiotics to their clients 2 weeks prior to the survey with amoxicillin (89.5\%), trimethoprim-sulfamethoxazole (septrin, 95.6\%), tetracycline (51.9\%), gentamicin (41.3\%), penicillin (56.9\%) [50]. The major amount of antimicrobials (65.83\%) dispensed on prescription in Rajshahi (Bangladesh) were macrolides, quinolones, metronidazoles and cephalosporins which are the most favourite drug of quacks, clients and pharmacists. The majority (92.9\%) of these drugs were broad spectrum and mostly penicillin [1]. The study of Chem et al. in Cameroon reported that the most prescribed antibiotics were Amoxicillin (29.29\%), Cotrimoxazole (19.08\%) and Metronidazole (15.59\%) in East West District facilities [20]. As previously discussed, differences in the incidence of infectious disease [36], sensibility of bacterial stains, factors related to patients, prescribers, medical representatives, antibiotic availability, and the environment could explained the above profiles of antibiotic classes prescribed or requested.

\section{Conclusion}

In our context, various media with prescription or without prescription permitted antibiotic requestors to access antibiotic available in private pharmacies. The 
antibiotic requestor is either the direct beneficiary or a relative beneficiary including the children. The regulation in force in prescription matter is not fully respected with regard to the mention of information concerning the prescriber, the patient and those related to medicine (dosage, route and rhythm of administration, and duration of treatment) whatever the health care facility and the category of health professional. Almost all ATBs' classes are prescribed in Lomé with a high frequency of beta-lactams, quinolones and 5-nitro-imidazoles. They are prescribed in all kinds of health care centers in which all categories of professionals prescribe them in any available media. Moreover, it is not rare to see a patient in a drugstore asking for ATBs because they feel the need of taking them. All those habits contribute to maintain and increase AMR cases. Access to antibiotics should be further controlled (prescription dispensing). Community should ban other media of obtaining antibiotics without a prescription and avoid particularly antimicrobial self-medication.

\section{Acknowledgements}

We would like to thank the pharmacy staff that took part in this study. We are also grateful to Professor Essowe K. Essizewa for reviewing the language quality of this work.

\section{Conflicts of Interest}

The authors declare no conflicts of interest regarding the publication of this paper.

\section{References}

[1] Saha, S. and Hossain, Md.T. (2017) Evaluation of Medicines Dispensing Pattern of Private Pharmacies in Rajshahi, Bangladesh. BMC Health Service Research, 17, 136. https://doi.org/10.1186/s12913-017-2072-Z

[2] Bennadi, D. (2013) Self-Medication: A Current Challenge. Journal of Basic and Clinical Pharmacy, 5, 19-23. https://doi.org/10.4103/0976-0105.128253

[3] Chaturvedi, V.P., Mathur, A.G. and Anand, A.C. (2012) Rational Drug Use-As Common as Common Sense? Medical Journal Armed Forces India, 68, 206-208. https://doi.org/10.1016/j.mjafi.2012.04.002

[4] World Health Organization (2002) Promoting Rational Use of Medicines: Core Components-WHO Policy Perspectives on Medicines. http://apps.who.int/medicinedocs/en/d/Jh3011e/2.html

[5] Shankar, P.R. (2009) Medicines Use in Primary Care in Developing and Transitional Countries: Fact Book Summarizing Results from Studies Reported between 1990 and 2006. Bull World Health Organ, 87, 804-805. https://doi.org/10.2471/BLT.09.070417

[6] Morgan, D.J., Okeke, I.N., Laxminarayan, R., et al. (2011) Non-Prescription Antimicrobial Use Worldwide: A Systematic Review. The Lancet Infectious Diseases, 11, 692-701. https://doi.org/10.1016/S1473-3099(11)70054-8

[7] Kamat, V.R. and Nichter, M. (1998) Pharmacies, Self-Medication and Pharmaceutical Marketing in Bombay, India. Social Science \& Medicine, 47, 779-794. 
https://doi.org/10.1016/S0277-9536(98)00134-8

[8] Kafle, K.K., Gartoulla, R.P., Pradhan, Y.M., et al. (1992) Drug Retailer Training: Experiences from Nepal. Social Science \& Medicine, 35, 1015-1025. https://doi.org/10.1016/0277-9536(92)90241-H

[9] Basak, S. and Sathyanarayana, D. (2010) Evaluating Medicines Dispensing Patterns at Private Community Pharmacies in Tamilnadu, India. Southern Med Review, 3, 27-31.

[10] Pathak, A., Mahadik, K., Dhaneria, S.P., et al. (2011) Antibiotic Prescribing in Outpatients: Hospital and Seasonal Variations in Ujjain. India. Scandinavian Journal of Infectious Diseases, 43, 479-488. https://doi.org/10.3109/00365548.2011.554854

[11] Kotwani, A. and Holloway, K. (2011) Trends in Antibiotic Use among Outpatients in New Delhi, India. BMC Infectious Diseases, 11, 99. https://doi.org/10.1186/1471-2334-11-99

[12] Kotwani, A., Roy Chaudhury, R. and Holloway, K. (2012) Antibiotic Prescribing Practices of Primary Care Prescribers for Acute Diarrhoea in New Delhi India. Value Health, 15, S116-S119. https://doi.org/10.1016/j.jval.2011.11.008

[13] Pathak, D., Pathak, A., Marrone, G., et al. (2011) Adherence to Treatment Guidelines for Acute Diarrhoea in Children Up to 12 Years in Ujjain India-A Cross-Sectional Prescription Analysis. BMC Infectious Diseases, 11, 32. https://doi.org/10.1186/1471-2334-11-32

[14] Eholié, S.P., Bissagnené, E. and Crémieux, A.-C. (2013) Du bon usage des antibiotiques en Afrique sub-saharienne. IMEA, Paris.

[15] Hansini Bhoobdasur, L. (2014) Automédication: L'abus d'antibiotiques peut s'avérer fatal. L'express. http://www.lexpress.mu/node/245250

[16] Salou, M., Assimadzi, K., Wateba, I.M., et al. (2011) Résistance aux antibiotiques des bactéries isolées en 2009 au laboratoire de bactériologie du CHU-Tokoin Lomé-Togo. Journal de la Recherche Scientifique de l'Université de Lomé, 13, 151-159.

[17] Dagnra, A.-Y., Akolly, K., Gbadoe, A., et al. (2007) Émergence des souches de salmonelles multirésistantes aux antibiotiques à Lomé (Togo). Médecine et Maladies Infectieuses, 37, 266-2669. https://doi.org/10.1016/j.medmal.2007.02.002

[18] de Vries, T.P.G.M., Henning, R.H., Hogerzeil, H.V. and Fresle, A. (1994) Good Prescribing. A Practical Manual. WHO/DAP/94.11, 142 p.

[19] Padget, M., Tamarelle, J., Herindrainy, P., et al. (2017) BIRDY Study Group. A Community Survey of Antibiotic Consumption among Children in Madagascar and Senegal: The Importance of Healthcare Access and Care Quality. Journal of Antimicrobial Chemotherapy, 72, 564-573. https://doi.org/10.1093/jac/dkw446

[20] Chem, E.D., Anong, D.N., Jane-Francis, K.T., et al. (2018) Prescribing Patterns and Associated Factors of Antibiotic Prescription in Primary Health Care Facilities of Kumbo East and Kumbo West Health Districts, North West Cameroon. PLoS ONE, 13, e0193353. https://doi.org/10.1371/journal.pone.0193353

[21] McClean, P., Tunney, M., Gilpin, D., et al. (2012) Antimicrobial Prescribing in Residential Homes. Journal of Antimicrobial Chemotherapy, 67, 1781-1790. https://doi.org/10.1093/jac/dks085

[22] Prah, J., Kizzie-Hayford, J., Walker, E., et al. (2017) Antibiotic Prescription Pattern in a Ghanaian Primary Health Care Facility. Pan African Medical Journal, 28, 214. https://doi.org/10.11604/pamj.2017.28.214.13940

[23] Diarra, K.F. (2007) Prescription, dispensation et disponibilité des antibiotiques à la 
pharmacie hospitalière du CHU du Point-G. Thèse de Pharmacie, Université de Bamako, Mali. http://www.keneya.net/fmpos/theses/2006/pharma/pdf/06P47.pdf

[24] Steinman, M.A., Landerfield, C.S. and Gonzales, R. (2003) Predictors of Broad-Spectrum Antibiotic Prescribing for Acute Respiratory Tract Infections in Adult Primary Care. JAMA, 289, 719-725. https://doi.org/10.1001/jama.289.6.719

[25] Bharathiraja, R., Sivakumar, S., Chelliah, L., et al. (2005) Factor's Affecting Antibiotic Prescribing Pattern in Pediatric Practice. The Indian Journal of Pediatrics, 72, 1-5. https://doi.org/10.1007/BF02731121

[26] Huang, A.M., Newton, D. and Kunapuli, A. (2005) Antimicrobial Stewardship Team Intervention in Adult Patients with Bacteremia and Candidemia. Clinical Infectious Diseases, 57, 1237-1245. https://doi.org/10.1093/cid/cit498

[27] Akkerman, A., Kuyvenhoven, M., Van der Wouden, J., et al. (2005) Prescribing Antibiotics for Respiratory Tract Infections by GPs: Management and Prescriber Characteristics. British Journal of General Practice, 55, 114-118.

[28] Cadieux, G., Tamblyn, R., Dauphinee, D., et al. (2007) Predictors of Inappropriate Prescribing among Primary Care Physicians. CMAJ, 177, 877-883.

https://doi.org/10.1503/cmaj.070151

[29] Charan, N., Chandra, D.S., Adiveni, T., et al. (2013) A Prospective Study: Factors Affecting Antibiotic Prescribing Pattern in Surgery Wards in RMMCH. Journal of Biomedical and Pharmaceutical Research, 2, 71-73.

[30] Kotwani, A., Wattal, C., Katewa, S., et al. (2010) Factors Influencing Primary Care Physicians to Prescribe Antibiotics in India. Family Practice, 27, 684-690.

https://doi.org/10.1093/fampra/cmq059

[31] Dekker, A.R., Verheij, T.J. and Velden, A.W. (2015) Inappropriate Antibiotic Prescription for Respiratory Tract Indications: Most Prominent in Adult Patients. Family Practice, 32, 401-407. https://doi.org/10.1093/fampra/cmv019

[32] Ritabul Salami, M.R., Hassali, M.A., Alrasheedy, A.A., et al. (2015) Physicians' Knowledge, Perceptions, and Behaviour towards Antibiotic Prescribing: A Systematic Review of the Literature. Expert Review of Anti-Infective Therapy, 13, 665-680. https://doi.org/10.1586/14787210.2015.1025057

[33] Erah, P.O., Olumide, G.O. and Okhamafe, A.O. (2003) Prescribing Practices in Two Health Care Facilities in Warri, Southern Nigeria: A Comparative Study. Tropical Journal of Pharmaceutical Research, 2, 175-182. https://doi.org/10.4314/tjpr.v2i1.14583

[34] World Health Organization (2001) WHO Global Strategy for Containment of Antimicrobial Resistance. WHO, Geneva.

[35] Radyowijati, A. and Haak, H. (2003) Improving Antibiotic Use in Low-Income Countries: An Overview of Evidence on Determinants. Social Science \& Medicine, 57, 733-744. https://doi.org/10.1016/S0277-9536(02)00422-7

[36] Kliemann, B.S., Levin, A.S., Moura, M.L., et al. (2016) Socioeconomic Determinants of Antibiotic Consumption in the State of São Paulo, Brazil: The Effect of Restricting Over-the-Counter Sales. PLOS ONE, 11, e0167885. https://doi.org/10.1371/journal.pone.0167885

[37] Van Boeckel, T.P., Gandra, S., Ashok, A., et al. (2014) Global Antibiotic Consumption 2000 to 2010: An Analysis of National Pharmaceutical Sales Data. The Lancet Infectious Diseases, 14, 742-750. https://doi.org/10.1016/S1473-3099(14)70780-7

[38] Potchoo, Y., Redah, D. and Guissou, I.P. (2009) Etude de la qualité de la prescription 
des médicaments au Togo: Résultats d'une enquête en milieu urbain à Lomé. Journal de la Recherche Scientifique de I Université de Lomé, Série D, 11, 123-128.

[39] Fofana, S., Sanogo, Z., Kaboré, L., et al. (2016) Regulatory Compliance of Medical Prescriptions in Bobo-Dioulasso, Burkina Faso. Indian Journal of Medical Research and Pharmaceutical Sciences, 3, 2349-5340.

[40] Bontemps, H., Fauconnier, J., Bosson, J.L., et al. (1997) Évaluation de la qualité de la prescription des médicaments dans un CHU. Journal of Clinical Pharmacy, 16, 49-53.

[41] Bertrand, D., Labarere, J. and François, P. (1999) Efficacité d'un programme d'amélioration des prescriptions médicamenteuses et des comptes-rendus d'hospitalisation dans un hôpital universitaire. Santé Publique, 11, 343-555.

[42] Ruchet, L. (2010) Evaluation de la qualité des ordonnances communautaires provenant de l'hôpital de l'enfance de Lausanne. Maîtrise universitaire en pharmacie. Université de Lausanne, $50 \mathrm{p}$.

[43] El Bara (2013) Etude de la conformité des prescriptions et de la délivrance des médicaments au niveau de 25 officines de la ville de Nouakchott. Mémoire de santé publique. Université de Nouakchott, $78 \mathrm{p}$.

[44] Shahaibi, N., Said, L., Kini, T., et al. (2012) Identifying Errors in Hand Written Outpatient Prescriptions in Oman. Journal of Young Pharmacists, 4, 267-272. https://doi.org/10.4103/0975-1483.104371

[45] Bohand, X., Simon, L., Perrier, E., et al. (2009) Frequency, Types, and Potential Clinical Significance of Medication-Dispensing Errors. Clinics, 64, 11-16. https://doi.org/10.1590/S1807-59322009000100003

[46] Lesar, T. (2006) Medication Prescribing Errors Involving the Route of Administration. Hospital Pharmacy, 41, 1053-1066. https://doi.org/10.1310/hpj4111-1053

[47] Jasim, A. (2014) Parental Self-Medication of Antibiotics for Children in Baghdad City. International Journal of Pharmacy and Pharmaceutical Sciences, 6, 485-489.

[48] Musey, K.L., Akafomo, K., Beuscart, C., et al. (1990) Autocontrôle de l'antibiothérapie. Evaluation d'un système de suivi informatisé. Médecine et Maladies Infectieuses, 20, 25-32. https://doi.org/10.1016/S0399-077X(05)81020-0

[49] Coulibaly, Y., Konate, A., Kone, D., et al. (2014) Étude de la prescription des antibiotiques en milieu hospitalier malien. Revue Malienne d'Infectiologie et de Microbiologie, No. 3, 2-8.

[50] Mbonye, A.K., Buregyeya, E., Rutebemberwa, E., et al. (2016) Prescription for Antibiotics at Drug Shops and Strategies to Improve Quality of Care and Patient Safety: A Cross-Sectional Survey in the Private Sector in Uganda. BMJ Open, 6, e010632. https://doi.org/10.1136/bmjopen-2015-010632 